\title{
ACANTHOGYRUS TILAPIAE INFECTIONS IN WILD AND CULTURED NILE TILAPIA OREOCHROMIS NILOTICUS
}

\author{
EBTSAM SAYED HASSAN ABDALLAH ${ }^{1}$; AMNA MOHAMED AL TAYIP ${ }^{2}$; SARY \\ KHALEEL ABD ELGHAFFAR NASR ${ }^{3}$; GEHAN MOHAMED SAYED ${ }^{4}$; AHMAD ABD ELHADY \\ ELKAMEL $^{1}$ \\ ${ }^{1}$ Fish Diseases and Management, Fish Diseases and Management, Faculty of Veterinary \\ Medicine, Assiut University, Assiut 71526, Egypt \\ ${ }^{2}$ Animal Health Research Institute, Department of Fish Diseases and Management, Assiut, Egypt \\ ${ }^{3}$ Department of Pathology, Faculty of Veterinary Medicine, Assiut University, Assiut 71526, Egypt \\ ${ }^{4}$ Animal Health Research Institute, Department of Parasitology, Assiut, Egypt
}

Received: 17 Augusts 2017; $\quad$ Accepted: 1 October 2017

\begin{abstract}
Acanthogyrus tilapiae (Baylis, 1948) was isolated from the intestines of wild (from River Nile) and cultured (from ponds beside River Nile) Nile tilapia Oreochromis niloticus in Assiut city, Egypt. The study extended over one year starting from December 2013 to November 2014. The overall infection rate was $12.84 \%$, while was $11.80 \%$ with a mean intensity of 4.70 in the wild fish, and was $13.19 \%$ with a mean intensity of 2.68 in the cultured fish. The highest infection rate was recorded in winter in both wild (36.1\%) and cultured (33.3\%) fish. Males have insignificantly higher infection rates than females in both wild and cultured fish. There was a positive correlation between fish length (age) and A. tilapiae infection rates where larger (older) fish showed significantly higher infection rates then younger fish. The parasite was found mainly in the anterior two thirds of the intestine with the lowest number of the parasite detected in the posterior third. Histopathologically, the intestine of fish infected showed parasitic enteritis with lytic necrosis in the intestinal mucosa which associated with eosinophilic cell reaction.
\end{abstract}

Key words: Acanthogyrus tilapiae, wild and cultured Oreochromis niloticus, Egypt.

\section{INTRODUCTION}

Acanthocephalans are a group of helminthes endoparasites that are commonly found in both marine and freshwater fish worldwide. Phylum acanthocephala includes at least 1,289 species of relatively small, vermiform, heterosexual endoparasites (Amin, 2013) with low specificities of their intermediate, definitive and transport hosts. Acanthogyrus (Acanthosentis) tilapiae has been reported from thirty species of cichlid (28 of the genus Tilapia) and three non-cichlid species in Chad, Tanzania, Uganda, Congo, Nigeria, Malawi, and Egypt (Amin and Hendrix, 1999). They are located in the host's intestines causing irreversible mechanical damage by attachment with the armed proboscis affecting the architecture of the intestinal tissue and pathological changes (Mehlhorn and Armstrong, 2001). In heavy infections, they can

Corresponding author: Dr. AHMAD ABD ELHADY ELKAMEL E-mail address: aelkamel@aun.edu.eg

Present address: Fish Diseases and Management, Fish Diseases and Management, Faculty of Veterinary Medicine, Assiut University, Assiut 71526, Egypt cause occlusion of the gut (Nickol, 2006). Parasites infecting African freshwater fishes require urgent attention; particularly those that infect economically important fish species which in many cases devalue their aesthetic quality and palatability. Thus, extensive research on parasites which might constitute serious problems on Nile tilapia, Oreochromis niloticus, will enhance the production as well as parasites control (Onyedineke et al., 2010).

The objectives of the present study are to investigate A. tilapiae infection rates and intensities as well as sex, age, and seasonal susceptibility of wild and cultured O. niloticus at Assiut, Egypt and to describe the pathological alterations associated with this infection.

\section{MATERIALS AND METHODS}

Fish sampling and clinical investigation of the fish: Two hundred and eighty-eight wild and cultured $O$. niloticus of different sexes and lengths were collected over a year from the beginning of December 2013 to the end of November 2014. Wild O. niloticus samples (12 fish/month, $\mathrm{n}=144$ ) were randomly collected by gill net from the River Nile and its tributaries, Assiut, 
Egypt. Cultured fish (12 fish/month, n=144) were collected from open-system fish ponds beside the River Nile. Fish were directly examined for any clinical signs, lesions and /or any abnormalities according to Noga (2010).

Postmortem examination: Fish were sorted out and identified to the species level using key provided by Holden and Reed (1972). Each fish was assigned a reference number to facilitate data recording. Body weight, standard length and sex of each fish were recorded. Fish were euthanized using clove oil (Kildea et al., 2004) and examined according to Dezfuli et al. (1998).

Parasitological examination: Each fish was dissected and the intestine was transferred to a petri dish containing physiological saline solution. Intestine was divided into three thirds, anterior, middle and posterior. Debris were gently removed and specimens were microscopically examined for presence of adult $A$. tilapiae using a dissecting stereomicroscope (Leica EZ4, China). Parasite were counted, stained with acetic acid alum carmine stain and identified to the species level according to Amin (2005). Parasites were photographed using Leica microscope (Leica DM 1000, Germany).

Epidemiological studies: Infection rates and seasonal, sex as well as age susceptibilities of wild and cultured $O$. niloticus were investigated over the study duration following the standard methods described by Margolis et al. (1982). Fish length were used as indicator of the fish age, where the examined fish were divided into two groups according to their standard lengths with the young group length range from $8.5-11 \mathrm{~cm}$ and the older group length range from $11.5-17.5 \mathrm{~cm}$. Infection rates were calculated as the number of infected hosts/ total number of the examined hosts $\times 100$. Mean intensity of infection was calculated as the total number of parasites divided by the number of infected hosts.

Histopathological examination: Intestinal sections infected with A. tilapiae were prepared and examined as previously mentioned by Sanil et al. (2011). Briefly, intestinal sections were fixed in $10 \%$ neutral buffer formalin, dehydrated in an ascending series of ethanol solutions. The specimens were impregnated in molten paraffin wax three times and later embedded in molten paraffin wax and allowed to solidify. The blocked tissues were sectioned (3-7 $\mu \mathrm{m})$ using a Leica Microtome (Leica, Wetzlar, Germany), mounted using DPX, stained using Hematoxylin and Eosin, examined under a light microscope (Nikon Eclipse 80i, Japan) and photographed.

Data Analysis: One and two-way ANOVA were used to analyze the data. All analyses were performed using the software programmed Graph Pads Prism ${ }^{\circledR} 5$ Software (version 5.01). $P$ value for each data analysis was recorded.

\section{RESULTS}

Clinical and parasitological examination: Intestines of $O$. niloticus infected showed either congestion with intestinal intussusception (Fig. 1A) or paleness, with gas distension (Fig. 1B). A. tilapiae was isolated from the three thirds of intestinal sections of both wild and cultured $O$. niloticus. Microscopically, the parasite was thorny-headed, club-shaped, elongated worm, small to moderate in size. The body surface consisted of a series of folds. Short, cylindrical proboscis located at the anterior end and characterized by three rows of curved hooks oriented posteriorly. The hooks of the second and third rings were smaller than of the anterior first one. The proboscis enters proboscis receptacle when it is retracted. Two unequal blind and compact lemnisci extended from the base of the proboscis (Fig. 2A). Separate sexes with their reproductive systems located in the posterior half of the trunk and extends to its posterior end. The male reproductive organ composed of two testes, two cement glands and a copulatory bursa, however the female reproductive organ consisted of uterine bell that is connected to the uterine proper through the uterine duct. The uterine proper carries mature and immature eggs (Fig. 2B). A funnel-shaped vagina was located at the end of the female (Fig 2. magnified area).

Infection rates of $\boldsymbol{A}$. tilapiae: Direct microscopic examination of the intestines revealed that $17(11.8 \%)$ out of 144 wild $O$. niloticus were infected with $A$. tilapiae with a mean intensity of 4.70 , while in cultured fish, 19 (13.19) out of 144 fish were infected with a mean intensity of 2.68. The intensity of $A$. tilapiae infections ranged from 1 to 15 in wild $O$. niloticus, and from 1 to 7 in cultured fish.

Seasonal susceptibility to A. tilapiae: Infection rates were variable in different seasons. The infection rates were highest $(13 / 36,36.1 \%)$ in winter, then significantly decreased to $4 / 36(11.1 \%)$ in spring, and dropped to $0 / 36(0 \%)$ in both the summer and autumn. In a similar pattern, the infection rates in cultured fish was significantly higher in winter $(12 / 36,33.3 \%)$ than in spring $(4 / 36,11.1 \%)$, summer $(2 / 36,5.5 \%)$, and autumn $(1 / 36,2.7 \%)$.

Sex susceptibility to $\boldsymbol{A}$. tilapiae: Males were insignificantly higher in their susceptibility to $A$. tilapiae infection than females in both wild and cultured $O$. niloticus in all seasons except for cultured fish in the summer, where females showed insignificantly higher susceptibilities (Table 1).

Age susceptibility to $A$. tilapiae: In the present study, there was a positive correlation between the fish age (using the standard length as an indicator) and A. tilapiae infection rates, where the infections increased with the increase in fish ages, lengths, (Fig. 3 ). Also, the A. tilapiae mean intensity increased with the length. 
Localization of $A$. tilapiae in fish intestine: The infection rates with $A$. tilapiae were the highest $(11 / 144,7.63 \%)$ in the middle third of the wild fish intestines, $5 / 144(3.47 \%)$ in the anterior third, while were lowest $(1 / 144,0.69 \%)$ in the posterior third. In cultured fish, the highest infection rates were 10/144 $(6.94 \%)$ in the anterior third, $8 / 144(5.55 \%)$ in the middle third, while were $1 / 144(0.69 \%)$ in the posterior third.

Histopathological examination: Intestines infected with A. tilapiae showed parasitic enteritis and lytic necrosis in the intestinal mucosa associated with eosinophilic cell infiltration (Fig. 4).

Table 1: Sex susceptibility of wild and cultured Oreochromis niloticus to Acanthogyrus (Acanthosentis) tilapiae infection.

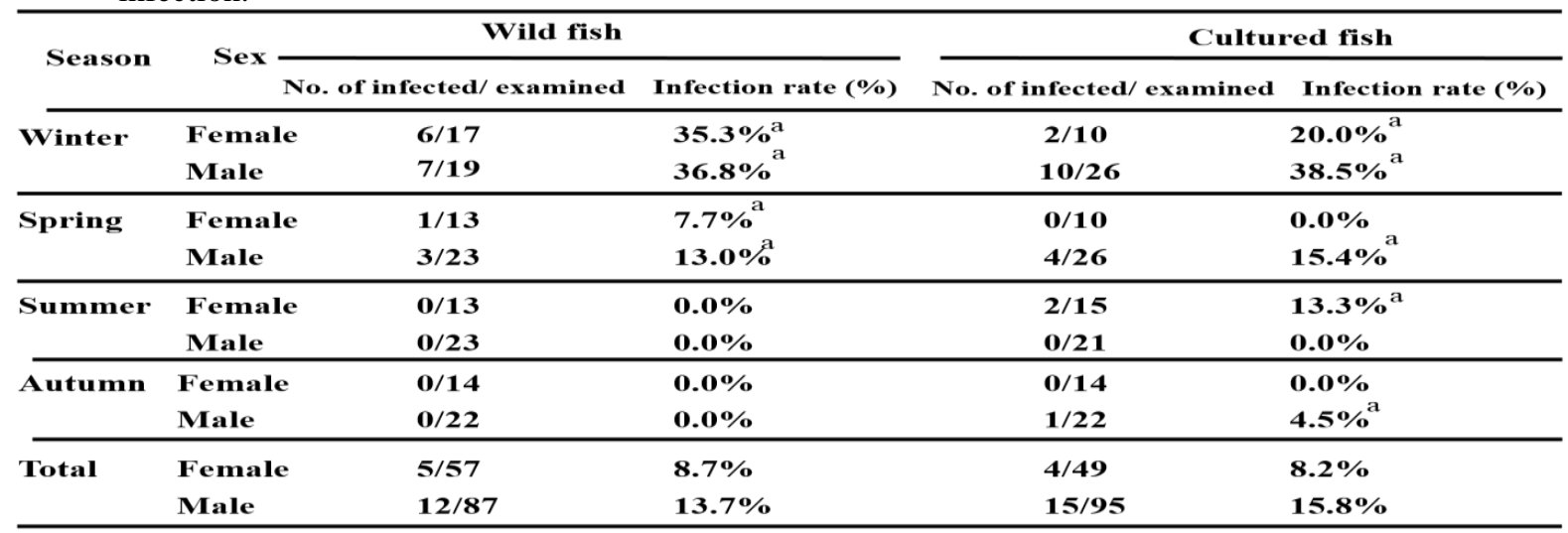

Different letters in the same column (for each season) indicate significant differences $(P<0.05)$.
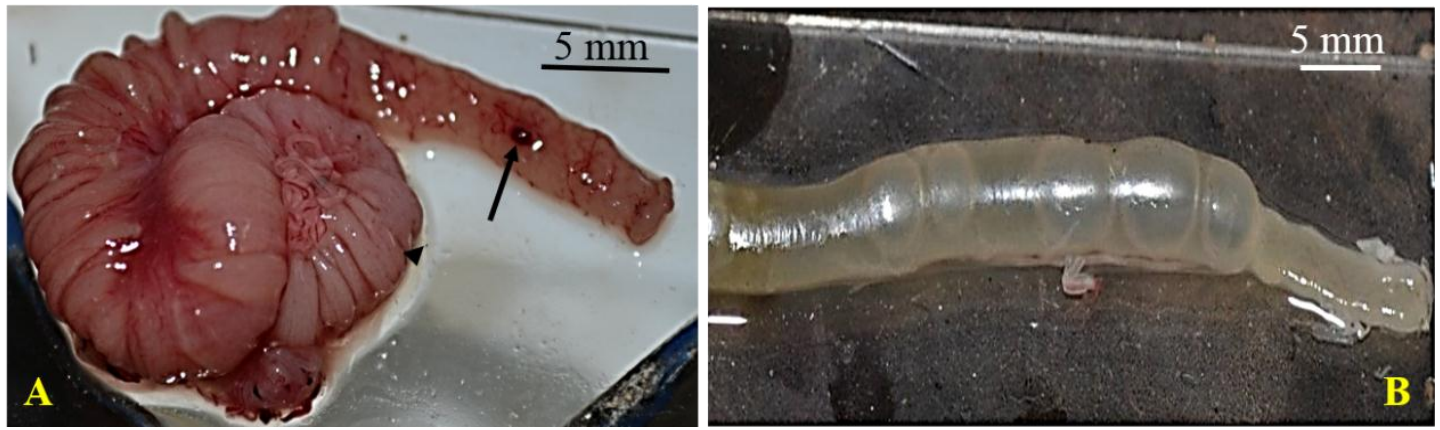

Fig. 1: A photograph of cultured Oreochromis niloticus intestine infected with Acanthogyrus (Acanthosentis) tilapiae showing congestion (black arrow) and intussusception (arrow head) (A) and pale intestine distended with gases (B).
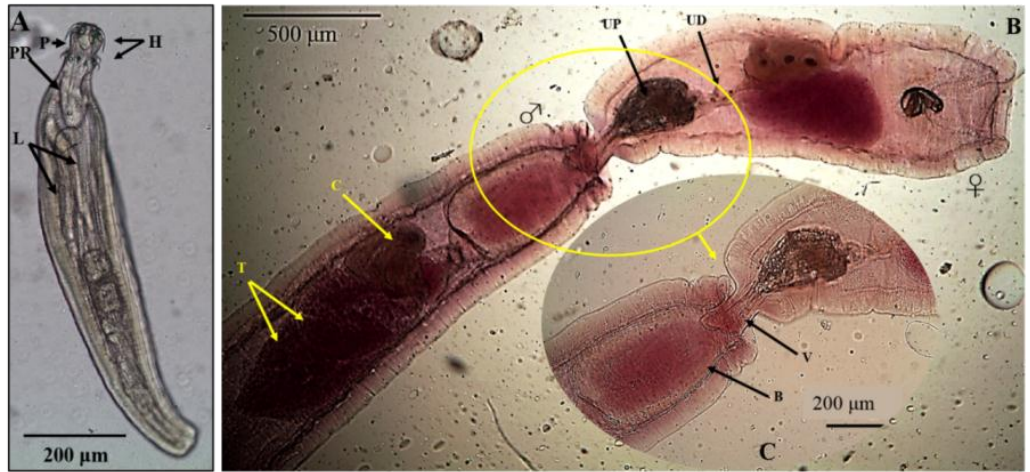

Fig. 2: A. A micrograph of a wet mount showing female Acanthogyrus (Acanthosentis) tilapiae recovered from a male Oreochromis niloticus intestine with proboscis $(\mathrm{P})$ that is located anteriorly and surrounded by three rows of rings of curved hooks $(\mathrm{H})$, Proboscis receptacle (PR), two lemnisci (L) that originate near the proboscis receptacle. B. A micrograph of A. tilapiae (male, $\sigma^{\lambda}$ ) with two testes (T) and two cement glands (C) in a copulatory position with a female (q) with an invaginated proboscis uterine bell (UB) that is connected to uterine proper (UP) through uterine duct (UD). The uterine proper carries mature and immature eggs (acetic acid alum carmine stain). The over magnified area shows funnel-shaped vagina (V) that is withdrawn into the body of the male with the invagination of the bursa (B). 


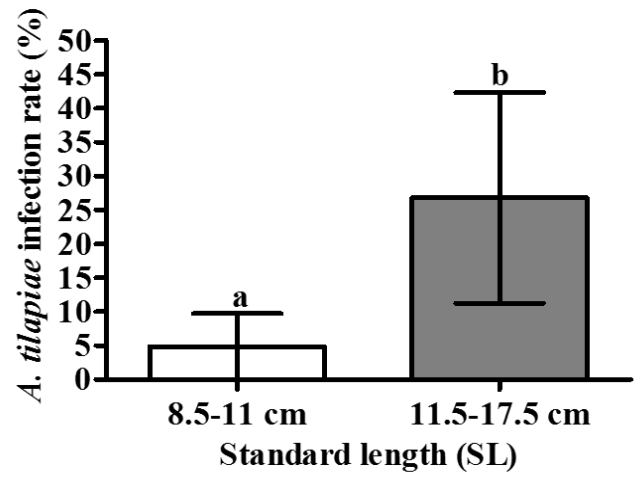

Wild Fish

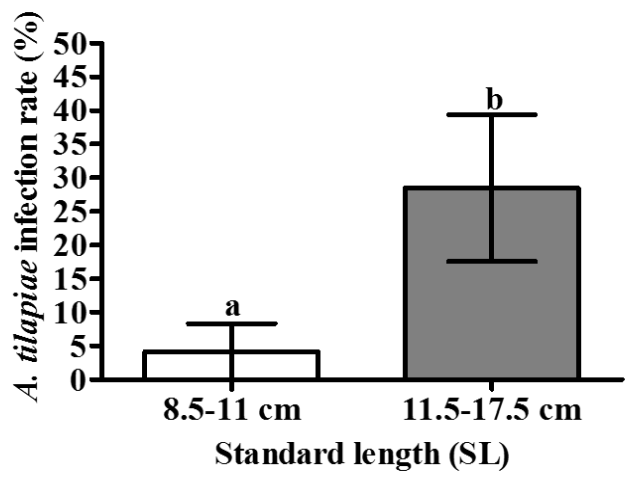

Cultured Fish

Fig. 3: A chart of age susceptibility of wild and cultured Oreochromis niloticus to Acanthogyrus (Acanthosentis) tilapiae infection. Columns represent the average infection rates for each fish length (as an indication for age). There was a significant at $P<0.05(P=0.0225)$ between young group with standard length range from $8.5-11$ and older group with standard length range from $11.5-17.5 \mathrm{~cm}$.
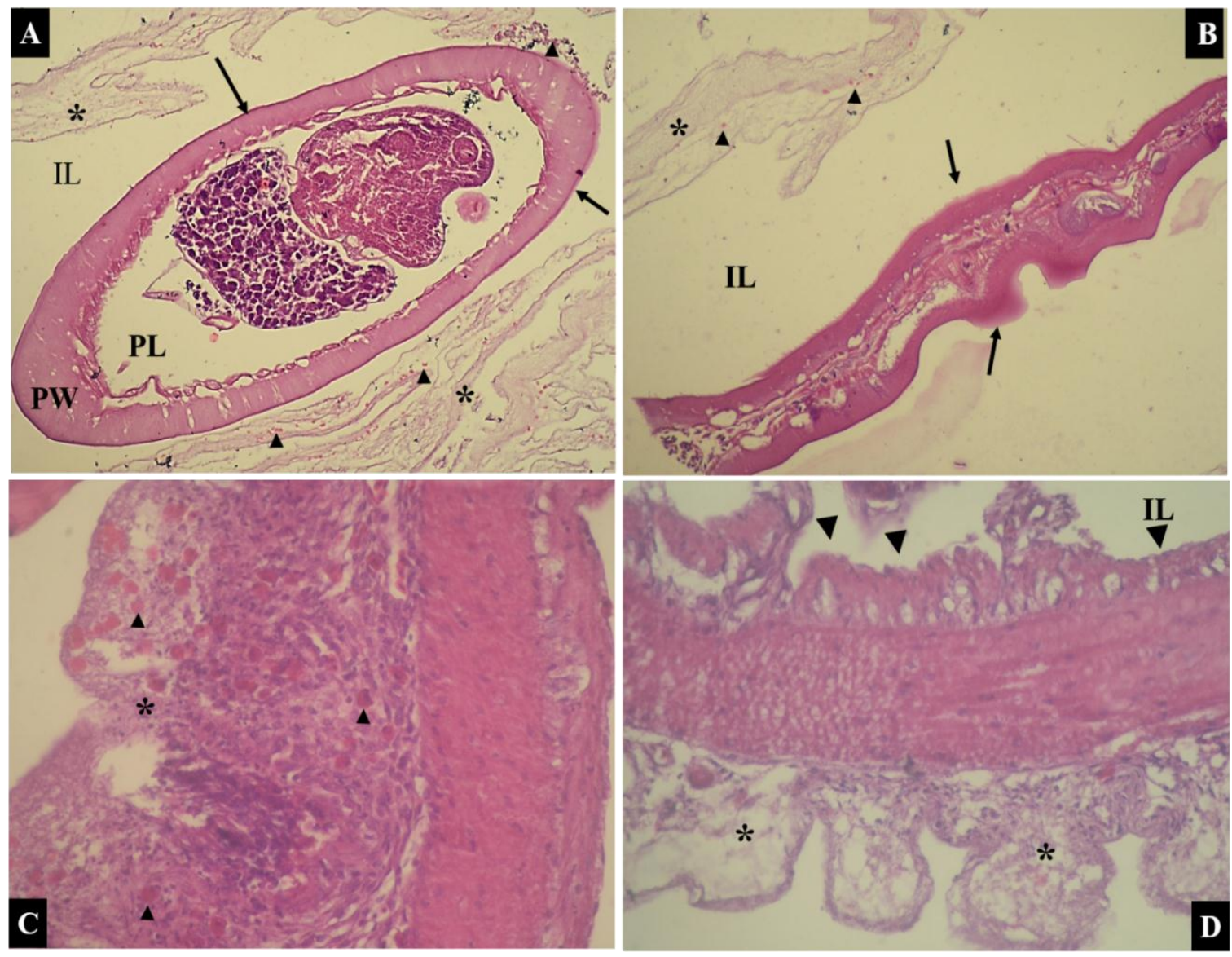

Fig. 4: A. Intestinal lumen of wild Nile tilapia Oreochromis niloticus showing cross section of the adult Acanthogyrus (Acanthosentis) tilapiae (arrow). Note marked necrosis in the intestinal mucosa (asterisk) associated with eosinophilic cell reaction (arrow head), H \&E X 10. B. Intestinal lumen showing longitudinal section of adult A. tilapiae (arrow). Note marked necrosis in the intestinal mucosa (asterisk) associated with eosinophilic cell reaction (head arrow), H \& E X 10. C. Intestinal wall showing parasitic enteritis with necrosis in the intestinal mucosa (asterisk) and the presence of inflammatory cell infiltration mostly eosinophil (arrow head), H \& E X 10. D. Intestinal wall showing parasitic enteritis with necrosis in the intestinal mucosa (arrow head) and marked inflammatory edema in the serosa (asterisk), H \& E X 10. IL: Intestinal lumen. PW: parasite wall, PL: parasite lumen. 


\section{DISCUSSION}

Wild $O$. niloticus feed mainly on phytoplankton and macrophytes (Dempster et al., 1993), zooplankton and benthic organisms (Njiru et al., 2004, Oso et al., 2006) that may act as intermediate hosts for several endohelminths. $O$. niloticus can be infected with A. tilapiae through feeding on cystacanth-infected crustaceans (Amin, 1998). Thus, this study was conducted to investigate the infection of wild and cultured $O$. niloticus with A. tilapiae in Assiut city, Egypt over one year.

Interestingly, there was no significant difference of the infection rates with adult intestinal A. tilapiae between cultured and wild fish. These results may be attributed to the nearly similar environmental conditions including sources of infections and contaminants that both wild and cultured fish live under, as the cultured $O$. niloticus, in this study, were reared in an open system in the River Nile. Although both wild and cultured fish were exposed to and live in almost the same water ecosystem, there were differences observed in the intensity of infection between wild and cultured fish. This may reflect varying levels of exposure to cystacanth-infected intermediate hosts and/or differences in the susceptibility of fish to the parasite as was suggested by Wilson et al. (2002).

The high infection rates in winter in both wild and cultured $O$. niloticus may be because of exhaustion and weakness of the fish caused by hibernation in the winter (Ibiwoye et al., 2004) that may result in lowering of their immune status and ability to resist infections. This suggestion is supported by the findings of Moharram (1980) who reported that the autumn and the winter were the two seasons in which the highest numbers of fish got infected with copepods and parasites. In addition, receding of water during the winter season (winter recession) may result in "habitat shrinking" and increase the chances that infective stages find the susceptible hosts. On the contrary, Eissa et al. (2010) reported that the highest infection rates with $A$. tilapiae was detected in the autumn season in both wild $(68 \%)$ and cultured $(54 \%)$ O. niloticus. These variations might be attributed to the differences in study location and nature of climate influencing the intermediate hosts.

The absence of infection in wild fish in the summer and autumn seasons may be a result of the high temperature making the environment unfavorable for the intermediate hosts which are one of the main determinants of acanthocephalan establishment in the final hosts (Kennedy, 2006). Therefore, a reduction in the numbers of potential intermediate hosts serving as prey for the fish hosts may affect the frequency that fish encounter the infective stage and account for the decrease in prevalence of acanthocephalan parasites.
Results of the present study showed that the infection rates with $A$. tilapiae in males were insignificantly higher than that of females counterpart in both wild and cultured fish as was reported by Aloo (2002), (Onyedineke et al., 2010). Males, as a stronger and more aggressive sex, could explore various habitats and feeding resources making them more vulnerable to encounter the infective stages of parasites. Also, this could be related to the fact that males have more exposure to increased turbulence and productivity, which may result in higher worm burden (Uhuo et al., 2014).

The present study proved that there is a positive correlation between A. tilapiae infection rates and the fish age. The significantly higher infections rates in larger (older) $O$. niloticus than in the smaller (younger) ones may be explained by the ability of older fish to accumulate more parasites in their intestine over time than do smaller fish. Also, large fish provide a large targets (intestine) surface area for invading larval stages of parasites than do smaller fish. Similar results were recorded by Aloo (2002), Mathenge (2010), Onyedineke et al. (2010) and Akoll et al. (2012) who reported that the infection rates increased with the increase of the age of the host. The host's sex and size significantly influence the dietary requirements, feeding rates, as well as habitat choice. Consequently, the exposure and susceptibility of fish to helminths differ across the size classes and between genders (Poulin, 1999, Reimchen and Nosil, 2001).

Acanthogyrus tilapiae was detected exclusively in the intestine of both wild and cultured fish. This could be due to the fact that most digestion activities take place in the intestine resulting in the excystment of the parasite cystacanth from the small aquatic crustacean (Onyedineke et al., 2010). Interestingly, A. tilapiae was found with the highest intensities in the first two thirds of the intestine. The $\mathrm{pH}$ and organisms milue of this area of the intestine may be more suitable for A. tilapiae than in the posterior part of the intestine. This suggestion is further supported by the finding that A. tilapiae was merely detected in the posterior third of the intestine in both wild and cultured fish.

The pathogenicity of adult A. tilapiae is mainly due to mechanical damage to the host's intestinal tissue caused by the multiple hooked proboscises used in attachment of the parasite to the host's intestinal lining. Also, the posteriorly oriented curved proboscis spines through which attachment to the host intestine is maintained may exacerbate the problem. This damage is usually followed by host immune responses like infiltration of eosinophils (Schelhaas, 1980), which was evident in the present study. In addition, parasite secretions may also lead to destruction of intestinal tissues leading to extensive inflammatory responses (Bayoumy et al., 2006). This explains the main pathological findings in the 
intestine of fish infected with A. tilapiae in the present study.

\section{REFERENCES}

Akoll, P.; Konecny, R.; Mwanja, W.W. and Schiemer, $F$. (2012): Infection patterns of Nile tilapia (Oreochromis niloticus L.) by two helminth species with contrasting life styles. Parasitology research 110:1461-1472.

Aloo, P. (2002): A comparative studyof helminth parasites from the fish Tilapia zillii and Oreochromis leucostictus in Lake Naivasha and Oloidien Bay, Kenya. Journal of helminthology 76:95-102.

Amin, O.M. (1998): Marine flora and fauna of the Eastern United States: Acanthocephala. In, Book 135. NOAA Technical Report NMFS

Amin, O.M. (2005): Occurrence of the subgenus Acanthosentis Verna andDatta, 1929 (Acanthocephala: Quadrigyridae) in Japan, with the description of Acanthogyrus (Acanthosentis) alternatspinus n. sp. and $A$. (A.) parareceptaclis $\mathrm{n}$. sp. from Lake Biwa drainage fishes and a key to the species of the subgenus. Systematic Parasitology 60:125-137.

Amin, O.M. (2013): Classification of the acanthocephala. Folia parasitologica 60:273305

Amin, O.M. and Hendrix, S.S. (1999): Acanthocephala of cichlids (Pisces) in Lake Malawi, Africa with a description of Acanthogyrus (Acanthosentis) malawiensis sp.n. (Quadrigyridae) from Labeo cylindricus Peters, 1852 (Cyprinidae). Journal of the Helminthological Society of Washington 66:47-55

Bayoumy, M.E.; El-Hady, A.; Osman, K. and Osman, H.A. (2006): Site adaptations of Acanthogyrus (Acanthosentis) tilapiae: Observations through light and scanning electron microscopy. Journal of veterinary science 7:339-342.

Dempster, P.; Beveridge, M. and Baird, D. (1993): Herbivory in the tilapia Oreochromis niloticus: a comparison of feeding rates on phytoplankton and periphyton. Journal of Fish Biology 43:385-392.

Dezfuli, B.; Capuano, S. and Manera, M. (1998): A description of rodlet cells from the alimentary canal of Anguilla anguilla and their relationship with parasitic helminths. Journal of Fish Biology 53:1084-1095.

Eissa, I.A.; Badran, A.F. and Mohamed, S.Y. (2010): Enteric Helminthes Infections in Cultured and Wild Oreochromis niloticus in Ismailia Province, Egypt. Journal of Agricultural and Veterinary Sciences 3.

Holden, W. and Reed, W.E. (1972): West African Freshwater fishes, Vol. Longmans Publishing Campany Limited, London.
Ibiwoye, T.I.I.; Balogun, A.M.; Ogunsisi, R.A. and Agbontale, J.J. (2004): Determination of the infection densities of nematode Eustrongylides in mud fish Clarias gariepinus and Clarias angullaris from Bida flood plain of Nigeria. . Journal of Applied Science and Environmental Management 8:39-44.

Kennedy, C.R. (2006):Ecology of Acanthocephala, Vol. Cambridge University Press, New York, USA.

Kildea, M.A.; Allan, G.L. and Kearney, R.E. (2004): Accumulation and clearance of the anaesthetics clove oil and AQUI-STM from the edible tissue of silver perch (Bidyanus bidyanus). Aquaculture 232: 265-277.

Margolis, L.; Esch, G.W.; Holmer, J.C.; Kuris, A.M. and Schad, G.A. (1982): The use of ecological terms in parasitology, (Report of an Ad Hoc Committee of the American Society of Parasitology). Journal of Parasitology 6133-8: 131.

Mathenge, C.G. (2010): Prevalence, intensity and pathological lesions associated with helminth infections in farmed and wild fish in upper tana river basin, Kenya. MVSc, University of Nairobi, Faculty of Veterinary Medicine.

Mehlhorn, H. and Armstrong, P.M. (2001): Encyclopedic reference of parasitology: Diseases, treatment, therapy, Vol 2. Springer Science andBusiness Media.

Moharram, S.G. (1980): Studies on Parasitic Fauna of Merluccius merluccius of Alexandria and its Effect on the General Condition of the Fish. M.Sc., Alexandria University, Faculty of Science.

Nickol, B.B. (2006): Phylum Acanthocephala. In: Woo P. T. K. (ed) Fish Diseases and Disorders. Protozoan and Metazoan Infections. CAB International, Wallingford, UK.

Njiru, M.; Okeyo-Owuor, J.; Muchiri, M. and Cowx, I. (2004): Shifts in the food of Nile tilapia, Oreochromis niloticus (L.) in Lake Victoria, Kenya. African Journal of Ecology 42:163170.

Noga, E.J. (2010): Fish Disease Diagnosis and Treatmaent.2nd edn. Edward J. Noga.

Onyedineke, N.E.; Obi, U.; Ofoegbu, P.U. and Ukogo, I. (2010): Helminth parasites of some freshwater fish from River Niger at Illushi, Edo State, Nigeria. Journal of American Science 6:16-21

Oso, J.; Ayodele, I. and Fagbuaro, O. (2006): Food and feeding habits of Oreochromis niloticus (L.) and Sarotherodon galilaeus (L.) in a tropical reservoir. World J Zool 1:118-121

Poulin, R. (1999): Body size vs abundance among parasite species: positive relationships? Ecography 22:246-250.

Reimchen, T. and Nosil, P. (2001): Ecological causes of sex-based parasitism in threespine 
stickleback. Biological Journal of the Linnean Society 73:51-63.

Sanil, N.; Asokan, P.; John, L. and Vijayan, K. (2011): Pathological manifestations of the acanthocephalan parasite, Tenuiproboscis $s p$. in the mangrove red snapper (Lutjanus argentimaculatus) (Forsskål, 1775), a candidate species for aquaculture from Southern India. Aquaculture 310: 259-266.

Schelhaas, D.P. (1980): Comparative Histopathology of Acanthocephan Infections in Some Freshwater Fishes. M.Sc. Thesis, University of North Dakota.

Uhuo, A.C.; Uneke, B.I.; Nwele, D.E.; Azi, S.O.; Ogiji, E.D. and Okereke, C.N. (2014): The prevalence of acanthocephalan parasites of Tilapian species in Cross River Basin Indibe Beach, Afikpo North Ebonyi State, Nigeria. Sky Journal of Biochemistry Research 3:042 045

Wilson, K.; Bjфmstad, O.N.; Dobson, A.P.; Merler, S.; Poglayen, G.; E., R.S.; Read, A.F. and Skorping, A. (2002): Heterogeneities in macroparasite infections: patterns and processes. In: Hudson P. J. ; Rizzoli, A. ; T., G. B.; Heesterbeek, H. and Dobson, A.P. (eds) Ecology of Wildlife Diseases, Oxford University Press Inc.

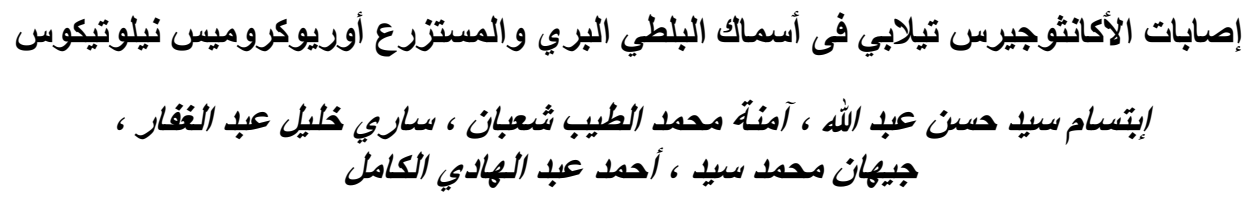

E-mail: aelkamel@aun.edu.eg_Assiut University web-site: www.aun.edu.eg

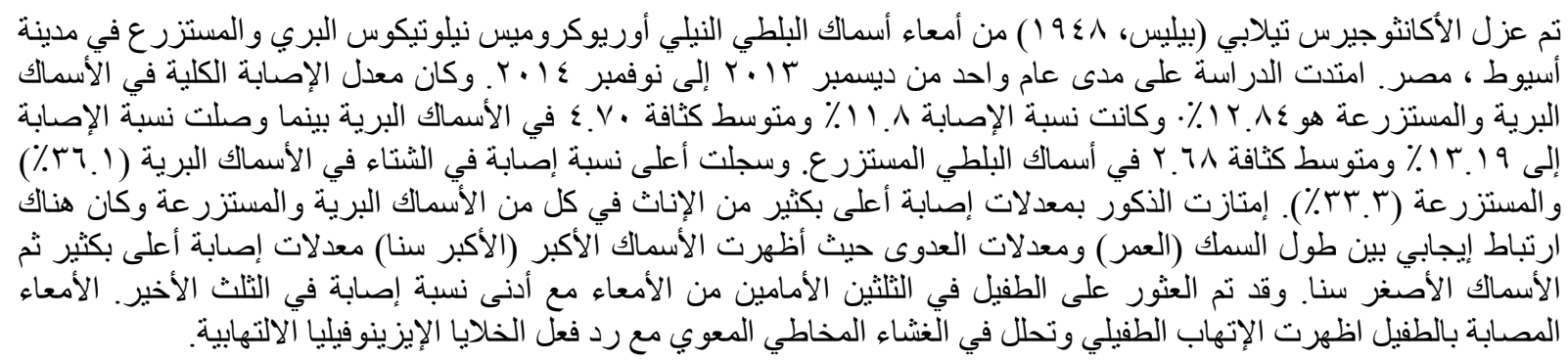

